\title{
Analytic salinity-temperature relations for the upper-thermocline waters of the eastern North Atlantic subtropical gyre
}

\author{
ÁNGELES MARRERO-DÍAZ ${ }^{1}$, ÁNGEL RODRÍGUEZ-SANTANA ${ }^{1}$, \\ FRANCISCO MACHÍN ${ }^{1,2}$ and JOSEP LLUIS PELEGRÍ ${ }^{2}$ \\ ${ }^{1}$ Universidad de Las Palmas de Gran Canaria, Campus Universitario de Tafira, 35017 Las Palmas de Gran Canaria, \\ Canary Islands, Spain. E-mail: amarrero@dfis.ulpgc.es \\ ${ }^{2}$ Institut de Ciències del Mar, CSIC, Passeig Marítim de la Barceloneta, 37-49, 08003 Barcelona, Spain.
}

\begin{abstract}
SUMMARY: We study the dependence of salinity on temperature in two by two degrees latitude-longitude boxes, for surface and upper-thermocline waters of the eastern North Atlantic subtropical gyre. The initial data set, from historical databases as well as from recent hydrographic cruises in the region, is carefully scrutinized to reject dubious measurements. We search for polynomial relations of variable degree between salinity and temperature, the optimal fit is selected as the polynomial with the lowest degree that satisfies several statistical criteria. An independent hydrographic cruise is used to confirm that the method performs substantially better than estimates from climatological data, and leads to relatively low deviations in geopotential anomaly and other derived quantities. An error propagation analysis using the Monte Carlo method shows equally good results.
\end{abstract}

Keywords: S-T relationship, eastern North Atlantic Subtropical Gyre (NASG), climatology, XBT probe, geostrophic transport.

RESUMEN: RELACIONES ANALÍTICAS ENTRE LA SALINIDAD Y LA TEMPERATURA PARA AGUAS DE LA TERMOCLINA SUPERIOR EN EL MARGEN ORIENTAL DEL GIRO SUBTROPICAL DEL ATLÁNTICO NORTE. - En este estudio caracterizamos la dependencia de la salinidad con la temperatura en cajas de dos por dos grados de latitud y longitud para aguas superficiales y de la termoclina superior en el margen oriental del giro subtropical del Atlántico Norte. El conjunto inicial de datos, procedente de bases de datos históricos, así como los procedentes de recientes campañas hidrográficas en la región, son cuidadosamente analizados para eliminar las medidas de calidad dudosa. Se analizan varias relaciones polinómicas de grado variable para la salinidad en función de la temperatura, eligiendo como ajuste óptimo aquel polinomio de menor grado que satisface diversos criterios estadísticos. Se utiliza una campaña hidrográfica independiente para confirmar que el método da resultados substancialmente mejores que estimaciones a partir de datos climatológicos, y que produce desviaciones relativamente bajas en la anomalía geopotencial y en otras magnitudes derivadas. Un análisis de la propagación del error usando el Método de Montecarlo muestra resultados igualmente buenos.

Palabras clave: relaciones analíticas S-T, margen oriental del Giro Subtropical del Atlántico Norte, climatologías, sondas $\mathrm{XBT}$, transporte geostrófico.

\section{INTRODUCTION}

An early insight into the possibility of using temperature-salinity (T-S) diagrams to infer dynamic properties was made by Stommel (1947). It was during the 70s, however, with the standard utilization of expandable bathythermographs (XBTs), that there began to be real interest in using temperature profiles in order to infer other oceanographic quantities. The approach (or S-T method) consisted in using historical data to obtain a mean T-S regional diagram and then use an objective method to estimate salinity from temperature (or potential temperature) values (Armi and Bray, 1982; Emery and Dewar, 1982; 
Siedler and Stramma, 1983; Zantopp and Leman, 1984). The method commonly employed was a cubic-spline adjustment, which required finding the node points and the third order polynomial coefficients at each point. The method resulted in a considerably large number of coordinates and coefficients and, unfortunately, these were usually not reported (see, however, Armi and Bray, 1982).

A magnitude commonly used to estimate the goodness of the S-T method is the standard deviation between the dynamic height estimated from temperature data, $d$, and that obtained with actual conductivity-temperature-depth (CTD) data, $d$. According to several authors the method is appropriate if $\overline{d-d^{\prime}} \leq 0.4 \mathrm{~m}^{2} \mathrm{~s}^{-2}$ (Stommel, 1947; Emery, 1975; Siedler and Stramma, 1983), and has been extensively applied to study the characteristics of circulation in regional oceans (Stommel, 1947; Emery, 1975; Emery and Wert, 1976; Emery and O'Brien, 1978; Flierl, 1978; Marrero-Díaz et al., 2001; Hernández-Guerra et al., 2002).

Siedler and Stramma (1983) carried out a careful study of the applicability of the S-T method, and analogous pressure-salinity and pressure-temperature-salinity approaches, to infer dynamic quantities for $5^{\circ} \times 5^{\circ}$ latitude-longitude boxes in the eastern North Atlantic subtropical gyre. They found that the S-T method was the best method for estimating geopotential anomalies for the top $500 \mathrm{~m}$ in most of the region between the African coast and $35^{\circ} \mathrm{W}$ and from $8^{\circ} \mathrm{N}$ to $41^{\circ} \mathrm{N}$.

Our work is based on Siedler and Stramma's (1983) findings about the applicability of T-S diagrams to infer dynamic quantities in the upper-thermocline layers of the eastern North Atlantic. We have aimed, however, at obtaining a set of analytic relationships that may be easily implemented to obtain salinity and dynamic quantities, while providing a good working knowledge of the errors involved. These analytic relations are obtained using extensive data sets gathered during the last two decades, which allows enhanced horizontal resolution $\left(2^{\circ} \times 2^{\circ}\right.$ latitude-longitude boxes) and increased reliability in the data quality.

Several publications have already used preliminary versions of these algorithms even though they were not yet published (Marrero-Díaz et al., 2001; Hernández-Guerra et al., 2002; Machín et al., 2006). Here we have decided to carefully discuss the method, including a comparison with climatology and an error analysis using an independent cruise, and to publish the resulting polynomials for the benefit of the oceanographic community that works on the eastern North Atlantic subtropical gyre.

\section{DATA AND METHOD}

The data set used for our analysis corresponds to CTD stations in the databases of the National Oceanographic Data Center and the Institut Francais de Recherche pour l'Exploitation de la Mer, as well as from hydrographic cruises carried out in the area by the Institut für Meereskunde and the Universidad de Las Palmas (R/V Ignat Pauvlynchenkov 1991; BIO Hesperides 1993, 1995, and summer 1997; R/V Meteor cruise P202). The area under study goes from $26^{\circ} \mathrm{N}$ to $38^{\circ} \mathrm{N}$ and from the African and Iberian Peninsula coast to $29^{\circ} \mathrm{W}$. The stations with water depths less than $100 \mathrm{~m}$ were eliminated to avoid the presence of platform water (Siedler and Stramma, 1983), so the initial number of CTD stations in the whole region was 2,091 with over 120,000 (salinitytemperature-pressure) data points.

The region was initially divided into 28 boxes of size $2^{\circ} \times 2^{\circ}$ in latitude and longitude, except the boxes near the coast that could be of somewhat different sizes (Fig. 1, recall that the boxes near the coast reach until the $100 \mathrm{~m}$ isobath). Due to the very different sources of CTD data we made a thorough effort to detect data of dubious quality. As a first step we drew T-S diagrams for all boxes and realized that

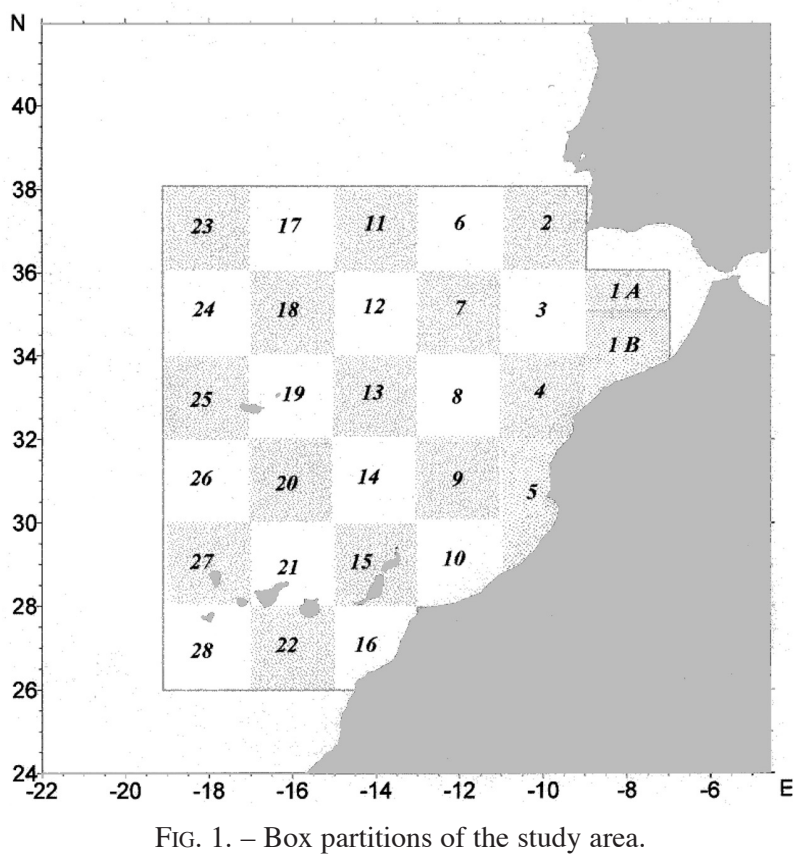




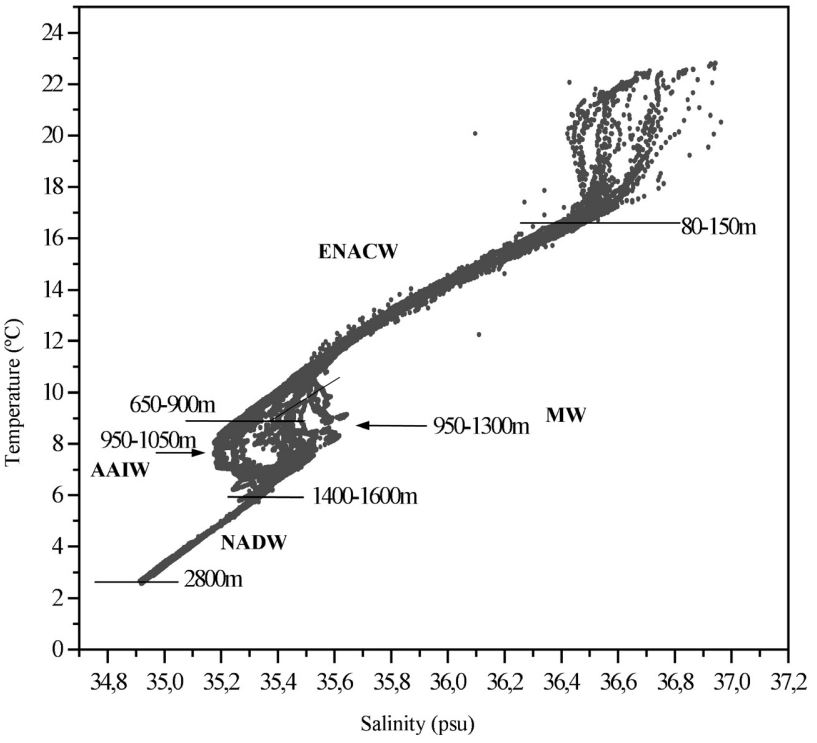

FIG. 2. - T-S diagram for box 15 , illustrating the different vertical domains of water masses characteristic of the region.

all data collected before 1970 showed very high dispersion, both within the data from before 1970 and compared with posterior data. For this reason these old data, prior to the utilization of CTDs, were discarded. Further, we detected several individual cruises that also showed large deviations from the mean behaviour and these were also discarded. In this way the initial data set was reduced to 488 stations with 109,784 data points.

Figure 2 shows a characteristic T-S diagram for the region, in this case corresponding to box 15 . On this diagram we may appreciate the presence of several water masses. The surface mixed-layer, down to 80-150 m, exhibits large variability because of the seasonal variation in ocean-atmosphere exchange. Below this layer and down to some $650-950 \mathrm{~m}$ we may find Eastern North Atlantic Central Water (ENACW), with a monotonic (and rather precise) temperature-salinity relationship. Centred at some $1000 \mathrm{~m}$ there is influence of Antarctic Intermediate Water (AAIW), characterized by a salinity minimum, though its presence is usually restricted to the eastern margin. Deeper, and down to some $1600 \mathrm{~m}$, there is a signal of relatively salty and warm Mediterranean Water (MW) that is commonly found in the northern margin. Further below we find Labrador Sea Water (LSW) and North Atlantic Deep Water (NADW) (Pérez et al., 2001).

We are interested in the possibility of extracting well-defined temperature-salinity relations that may allow us to infer dynamic properties from XBT data. Due to this, and since most commonly available
XBT data goes down only to $760 \mathrm{~m}$ (T7 or Deep Blue type probes), we decided to cut the data set at a maximum depth of $750 \mathrm{~m}$ (or even less in the northeastern boxes where MW has a shallow influence). The upper limit was chosen as the sea surface, despite the seasonal variability inherent in the existence of the surface mixed layer, because of the difficulty in defining an upper limit for ENACW. Note that the shallowness of the region under consideration makes it unnecessary to use potential temperature in place of in situ temperature.

After exploring several possibilities we chose to express the salinity $S$ as a polynomial of temperature $T$ with variable degree $k$, of the type $S(T)=B_{0}+B_{1} T$ $+B_{2} T^{2}+\ldots+B_{k} T^{k}$. The best polynomial fit is selected as the one with the lowest degree that satisfies both the Student and Fisher tests, and whose residuals show no significant improvement as compared with higher-order polynomials. To calculate the best polynomial fit we have used all the data within each box regardless of their season. This is because the temporal distribution of the data is seldom sufficient to attempt such a seasonal analysis. However, in the instances where enough data were available for a temporal analysis it turned out that the seasonal variation was practically negligible.

\section{RESULTS}

\section{Analytic relations}

Table 1 shows the coefficients of the best polynomials fit for all boxes. For each box we also present the adjusted multiple correlation coefficient, $R_{A}^{2}$, the standard deviation, $s d$, and the number of data points used for the calculations, $n$. The last column indicates the maximum depth that the relationship may be applied, this limitation usually caused by the appearance of MW above $750 \mathrm{~m}$. Polynomials range between the third and sixth degree, although in most boxes the best polynomial fit is of the fifth degree. It is important to keep in mind that for predictive purposes all calculations must be performed maintaining the same number of decimal digits as shown in the tables. It may also be observed that there are some boxes without values (boxes 2, 3, 6, 7, 12, 18, 24 and 25) simply because there was not enough data available to produce a reliable polynomial. Figure 3 illustrates, as an example, the data points and adjusted polynomial curve for box 21 . 
TABLE 1. - Coefficients for the best polynomial fit in each box. Also shown are the adjusted multiple correlation coefficient, $R_{A}^{2}$, the standard deviation, $s d$, the number of data points used for the calculations, $n$, and the maximum depth (if less than $750 \mathrm{~m}$ ) for which the polynomial may be used.

\begin{tabular}{|c|c|c|c|c|c|c|c|c|c|c|c|}
\hline \multirow{2}{*}{ Box } & \multirow[b]{2}{*}{$B_{o}$} & \multirow[b]{2}{*}{$B_{1}$} & \multirow[b]{2}{*}{$B_{2}$} & \multicolumn{2}{|c|}{ Coefficient } & \multirow[b]{2}{*}{$B_{5}$} & \multirow[b]{2}{*}{$B_{6}$} & \multirow[b]{2}{*}{$R_{A}^{2}$} & \multirow[b]{2}{*}{$s d$} & \multirow[b]{2}{*}{$n$} & \multirow[b]{2}{*}{ Depth } \\
\hline & & & & $B_{3}$ & $B_{4}$ & & & & & & \\
\hline $1 \mathrm{~A}$ & 182.388 & -43.393 & 5.0111 & -0.28305 & 0.0078555 & -0.000085903 & & 0.9894 & 0.0285 & 1313 & $500 \mathrm{~m}$ \\
\hline 1B & 99.873 & -19.5315 & 2.29441 & -0.130646 & 0.0036352 & -0.000039663 & & 0.9902 & 0.0335 & 1895 & \\
\hline 3 & & & & & & & & & & & \\
\hline 4 & 47.169 & -3.0740 & 0.27646 & -0.009263 & 0.0000541 & 0.000001808 & & 0.9900 & 0.0372 & 2297 & \\
\hline 5 & 9.864 & 9.3388 & -1.35836 & 0.097184 & -0.0033681 & 0.000045174 & & 0.9890 & 0.0357 & 2652 & \\
\hline 8 & 46.751 & -3.173 & 0.3134 & -0.012746 & 0.00018729 & & & 0.9957 & 0.0289 & 424 & \\
\hline 9 & 23.713 & 4.5795 & -0.71051 & 0.053616 & -0.00192303 & 0.000026311 & & 0.9887 & 0.0392 & 3243 & \\
\hline 10 & -19.803 & 20.2109 & -2.91734 & 0.206327 & -0.0070962 & 0.000094928 & & 0.9925 & 0.0339 & 2241 & \\
\hline \multirow{2}{*}{\multicolumn{12}{|c|}{0.00120295}} \\
\hline & & & & & & & & & & & \\
\hline 13 & 38.912 & 0.163 & -0.2178 & 0.027674 & -0.0012990 & 0.000021187 & & 0.9997 & 0.0068 & 46 & \\
\hline 14 & 62.091 & -7.351 & 0.7290 & -0.03061 & 0.0004669 & & & 0.9872 & 0.0434 & 89 & \\
\hline 15 & -7.2074 & 15.6725 & -2.26773 & 0.1602812 & -0.00548438 & 0.0000727126 & & 0.9927 & 0.0376 & 9228 & \\
\hline 16 & -3.0228 & 14.3996 & -2.13044 & 0.154211 & -0.00540650 & 0.0000734361 & & 0.9897 & 0.0406 & 12801 & \\
\hline 17 & -1280.9 & 540.2 & -91.51 & 8.187 & -0.40785 & 0.010727 & -0.00011640 & 0.9750 & 0.0361 & 297 & $500 \mathrm{~m}$ \\
\hline \multicolumn{12}{|c|}{$0.0001+010$} \\
\hline 19 & 67.254 & -8.7378 & 0.88178 & -0.039562 & 0.0007495 & -0.000003757 & & 0.9992 & 0.0133 & 378 & \\
\hline 20 & 52.511 & -4.559 & 0.4324 & -0.01704 & 0.0002426 & & & 0.9902 & 0.0479 & 79 & \\
\hline 21 & 2.914 & 11.996 & -1.7363 & 0.12229 & -0.00414887 & 0.000054343 & & 0.9957 & 0.0291 & 17384 & \\
\hline 22 & 2.2928 & 11.84155 & -1.67026 & 0.1151630 & -0.00383465 & 0.0000493518 & & 0.9918 & 0.0413 & 47285 & \\
\hline 23 & -2427.1 & 1001.5 & -168.27 & 14.947 & -0.74026 & 0.019384 & -0.00020972 & 0.9583 & 0.0463 & 336 & $500 \mathrm{~m}$ \\
\hline \multicolumn{12}{|l|}{24} \\
\hline 25 & & & & & & & & & & & \\
\hline 26 & 39.360 & -0.962 & 0.07312 & -0.001562 & & & & 0.9878 & 0.0528 & 49 & \\
\hline 27 & 12.2611 & 8.4113 & -1.20014 & 0.083220 & -0.00276409 & 0.000035274 & & 0.9944 & 0.0361 & 3962 & \\
\hline 28 & -22.878 & 20.1305 & -2.73657 & 0.182121 & -0.00588820 & 0.000074004 & & 0.9942 & 0.0372 & 1959 & \\
\hline
\end{tabular}

In order to have alternative polynomials for the boxes where there are insufficient (or few) data points, we have looked at several combinations of data from adjacent boxes. In our choice of the many different possibilities we have considered both geo-

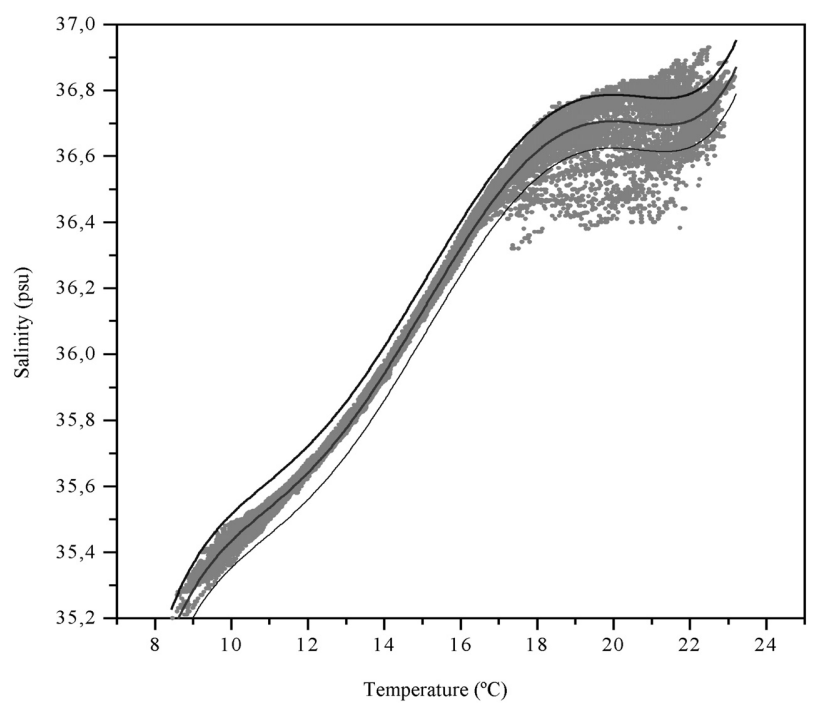

FIG. 3. - Polynomial adjustment (thick line) to data points in box 21. The enveloping lines correspond to one standard deviation. graphical proximity and the number of available data points. As a (subjective) criterion to infer these new polynomial coefficients we have requested a minimum of one high-resolution CTD station, or several bottle stations, for a total of at least 100 data points per box. Furthermore, we have avoided merging data from a box that had many more points than the other boxes in the combination. An additional dynamic criterion is the requirement that the circulation regime must not show rapid changes between neighbouring areas (an "area" now being a combination of boxes). This criterion has been applied studying all possible combinations of neighbouring individual boxes and examining the behaviour of stations that are in the vicinity of two areas. These stations must have similar density-depth profiles regardless of the area they are assigned, i.e. independent of the chosen relationship. Table 2 illustrates the new coefficients, together with the corresponding statistical quantities, for those combined boxes that provide the best statistical results. Hence, at the expense of decreasing the horizontal resolution, this table provides alternative polynomial expressions for boxes 2, 3, 6, 7, 12, 18, 24 and 25 . 
TABLE 2. - Best coefficient fit for combined boxes, all quantities are as in Table 1.

\begin{tabular}{|c|c|c|c|c|c|c|c|c|c|c|}
\hline Box & $B_{o}$ & $B_{I}$ & $B_{2}$ & $B_{3}^{\text {Coeff }}$ & ient $B_{4}$ & $B_{5}$ & $B_{6}$ & $R_{A}^{2}$ & $s d$ & $n$ \\
\hline $2-3-6-7$ & 69.519 & -9.466 & 0.9580 & -0.041664 & 0.0006645 & & & 0.9714 & 0.0525 & 322 \\
\hline $12-19$ & 68.895 & -9.322 & 0.9620 & -0.044832 & 0.000914 & -0.00000574 & & 0.9961 & 0.0297 & 424 \\
\hline $17-18-23-24$ & -2543.5 & 1051.5 & -177.14 & 15.780 & -0.7838 & 0.02059 & -0.0002234 & 0.9596 & 0.0454 & 633 \\
\hline $19-20-25-26$ & 53.141 & -4.278 & 0.3348 & -0.007108 & -0.0001830 & 0.000006528 & & 0.9947 & 0.0368 & 506 \\
\hline
\end{tabular}

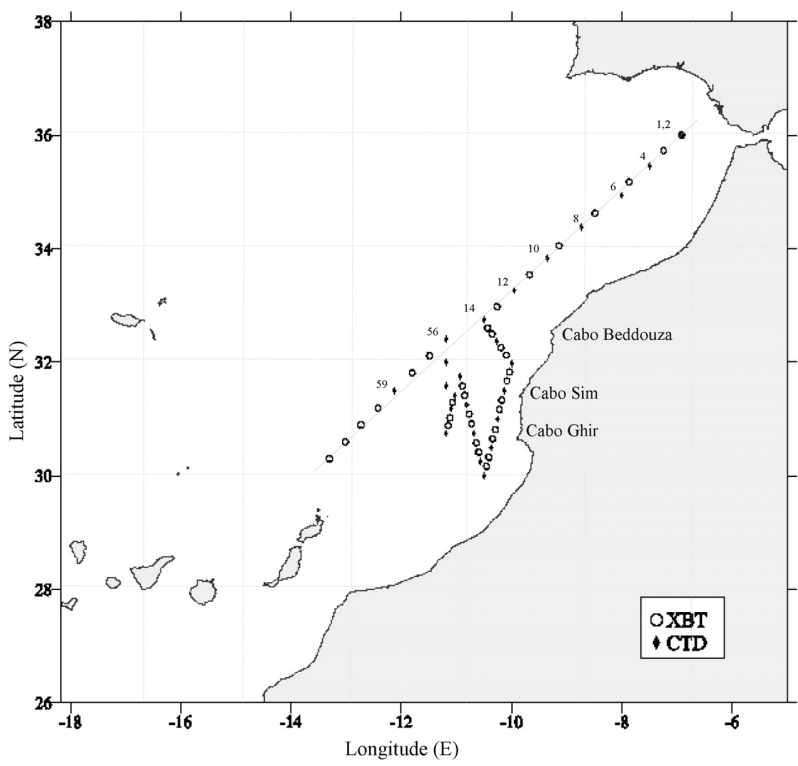

FIG. 4. - Map showing the location of the independent hydrographic section.

\section{Comparison with climatology}

We may wonder whether the procedure developed here has substantial advantages compared with using climatological data sets. A first advantage may be related to the easiness in our method as compared with the more laborious procedure of obtaining salinity from the regularly-spaced temperature and depth values in a climatological database. The climatological data has a spatial resolution usually of $1^{\circ}$ latitude/longitude (Levitus et al., 1994; Conkright et al., 2002), so that any station will be no more than $0.5^{\circ}$ away in latitude/longitude. This provides spatial resolution that is twice as good as the spatial resolution from our $2 \times 2^{\circ}$ boxes, without any need for interpolation. However, climatological data is usually given at standard depths, which leads to very low temperature resolution, typically of about only $0.5^{\circ} \mathrm{C}$. For NACW a $0.25^{\circ} \mathrm{C}$ deviation would immediately lead to a salinity error as large as $0.1 \mathrm{psu}$, hence forcing the user to develop some sort of interpolation procedure.
The second and most important advantage of our diagnostic algorithms, compared with using a climatological database, would rely on improved accuracy. To examine this aspect we have used an independent CTD cruise (independent in the sense that the data have not been used to obtain the analytic relations) carried out between the Iberian Peninsula and the Canary Islands (BIO Hespérides autumn 1997, Fig. 4), such that it runs through boxes 1, 4, and 9. The climatological data used here is World Ocean Atlas 2001, with $1^{\circ}$ latitude/longitude resolution (Conkright et al., 2002). We use the climatological data from those positions closest to the in situ profiles and obtain a so-called climatological salinity that may be compared with both the in situ salinity and the salinity inferred from the polynomials (Fig. 5). The separation distance between the actual station location and the nearest climatology grid point ranges between 0 (station 4) and $65 \mathrm{~km}$ (station 6), the mean being about $30 \mathrm{~km}$.

We first note that, as anticipated, the climatology provides data points with low resolution in the temperature domain, while the algorithms provide values for any desired temperature. Additionally, the climatology has no temperature data for $T \geq 19^{\circ} \mathrm{C}$ so in principle it could not provide predictions for this temperature range, which for this region represents the top $100 \mathrm{~m}$ (Pelegrí et al., 2005). This contrasts with the algorithm predictions that provide reasonably good predictions for this temperature range. In the temperature range $12^{\circ} \mathrm{C}<T<19^{\circ} \mathrm{C}$ both the $\mathrm{S}-\mathrm{T}$ algorithms and the climatology appear to do reasonably well in most stations, although in the northernmost stations (1 through 8) the performance of the climatology is clearly much worst. For waters with $T \leq 12^{\circ} \mathrm{C}$ climatology generally does better than the algorithms, apparently because of the presence of MW and/or AAIW.

In order to quantify the predictive skills of both climatology and the algorithms we have computed a density error, $\delta \sigma$, as the difference between the potential density calculated using either method and 


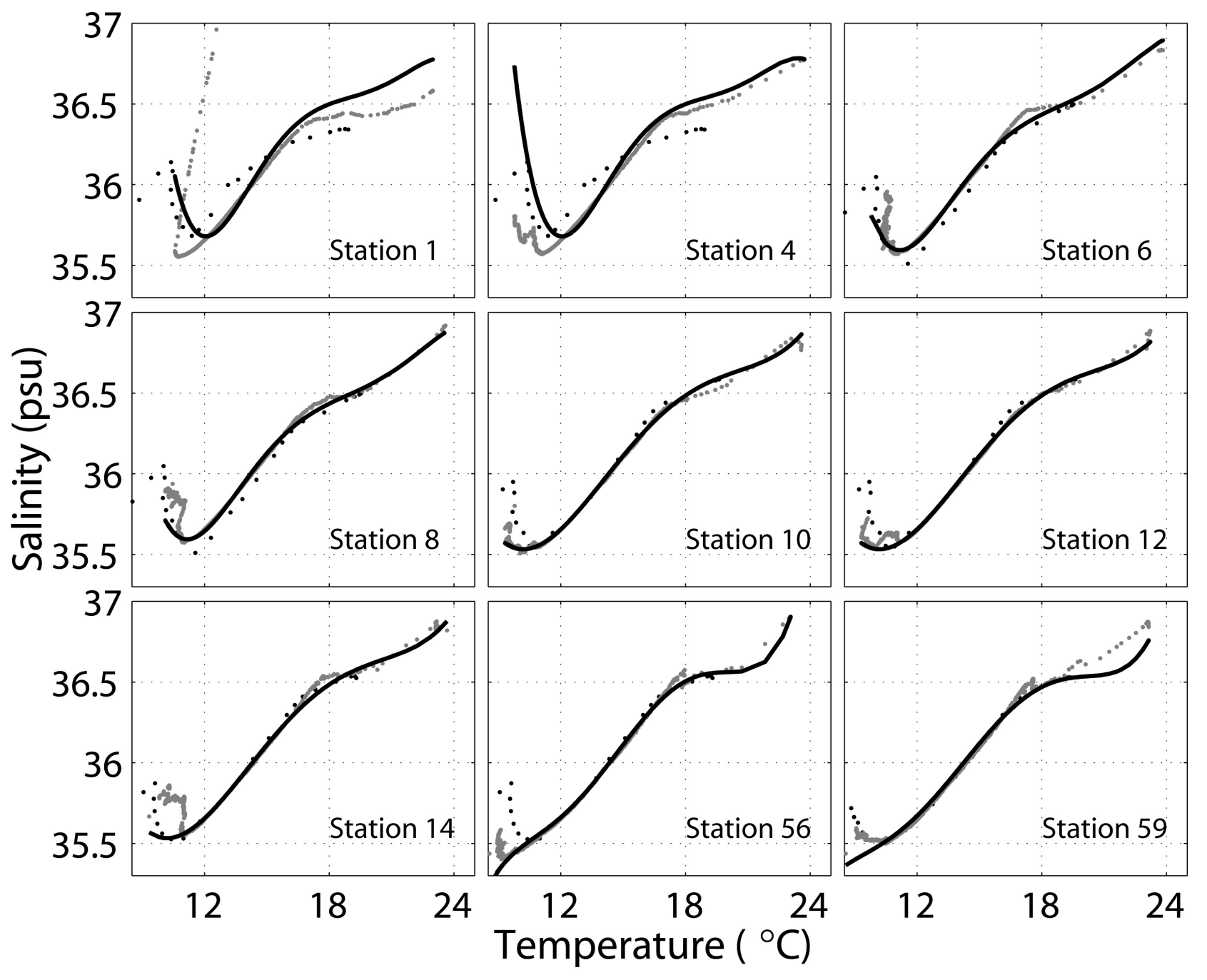

FIG. 5. - S-T plots comparing in situ data (gray-dot) during the Hesperides 1997 cruise, climatological data (black-dot) and polynomial fit to in situ data (black line).

the in situ potential density (Fig. 6). All data points are then used to compute the average and standard deviations. When using the climatology, the density error is very small in the $T \leq 12^{\circ} \mathrm{C}(0.00 \pm 0.04)$ and remains moderate in the $12^{\circ} \mathrm{C}<T<19^{\circ} \mathrm{C}$ range $(0.02 \pm$ $0.08)$, but increases greatly for warmer waters, $T \geq 19^{\circ} \mathrm{C}(0.81 \pm 0.22)$ (Fig. 6, left). With the algorithms the density error is moderate for $T \leq 12^{\circ} \mathrm{C}$ $(0.03 \pm 0.10)$, essentially because of the contribution of a few stations with intermediate-type waters, but decreases to small values in the $12^{\circ} \mathrm{C}<T<19^{\circ} \mathrm{C}(0.01 \pm 0.09)$ and $T \geq 19^{\circ} \mathrm{C}(0.01 \pm$ 0.07 ) ranges (Fig. 6, right). Station 1 has a very intense signal of $\mathrm{MW}$ that reaches temperatures greater than $12^{\circ} \mathrm{C}$; by simply removing this station's data below $690 \mathrm{~m}$ the statistics improve substantially in the $12^{\circ} \mathrm{C}<T<19^{\circ} \mathrm{C}$ range: $0.00 \pm 0.02$. If we recalculate the statistics by removing stations
1, 4 and 6, where significant MW is found, we find a improvement as follows: $-0.01 \pm 0.03$ for $T<12^{\circ} \mathrm{C}$, and $0.00 \pm 0.01$ for $12^{\circ} \mathrm{C}<T<19^{\circ} \mathrm{C}$.

The overall results illustrate that the algorithms perform better than climatology, except in the presence of MW or AAIW. Since these intermediate waters are only found in the eastern boxes, and since our method only aims at reproducing the NACW T$\mathrm{S}$ relationships, we may conclude that the algorithms are easier to use and provide results substantially better than climatology.

\section{Monte Carlo simulation}

The classical error propagation technique accumulates the individual error of each variable and leads to estimates of the maximum errors. Using a Monte Carlo type simulation of the measurement errors may 

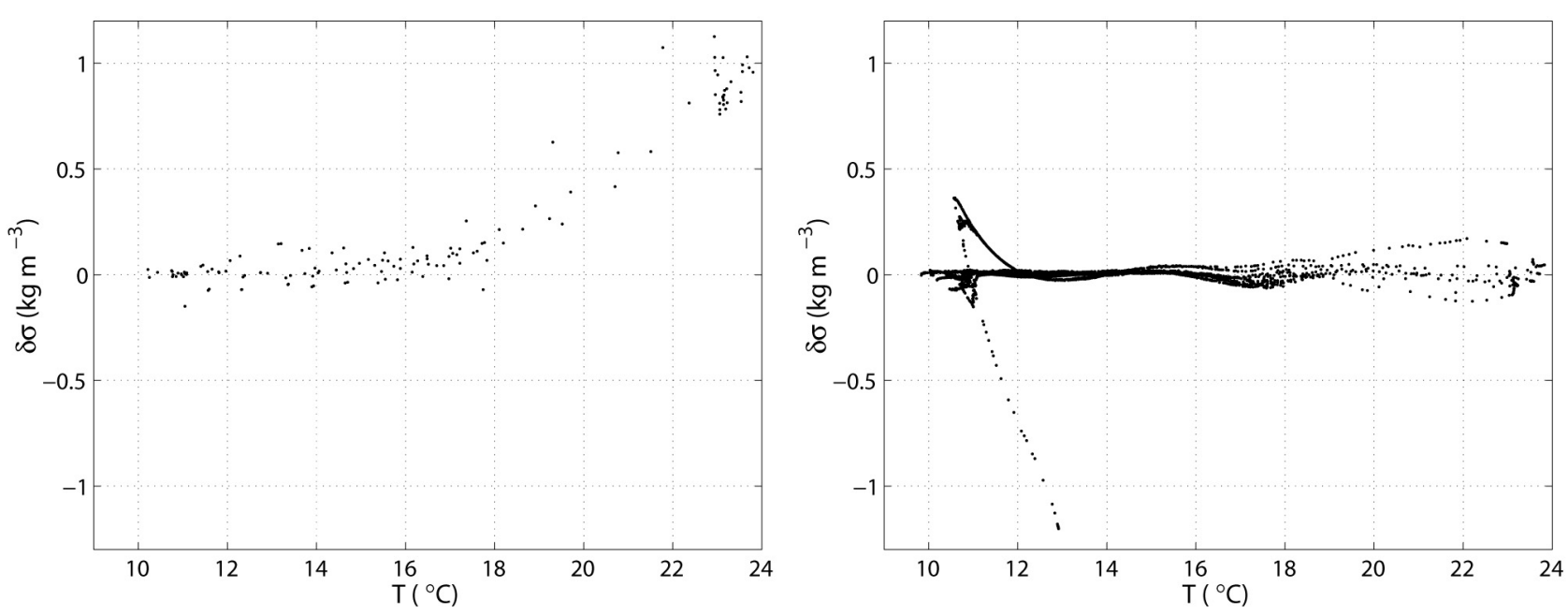

FIG. 6. - Density error $(\delta \sigma)$ calculated as the difference between potential density estimated from the climatological data minus in situ potential density (left), and as the difference between potential density estimated from the polynomial fits minus in situ potential density (right).

produce more realistic estimates of the mean errors (e.g. Rodríguez-Santana et al., 1999). The method assumes that the measured variables are the true values, and generates artificial ensembles for them through an appropriate distribution function that uses estimates of the measurement errors (Hammersley and Handscomb, 1964). The ensemble of inferred quantities is then obtained from the direct quantities through the corresponding functional relationships.

To apply this technique we have created, for each ( $T, S$, depth) data point, a sample of $5000(T, S$, depth) values that follow normal distributions. The standard deviations for these distributions are a function of position, given either by the instrument accuracy (depth and temperature) or as the standard deviation in the polynomial fit (salinity) at that point. For each data point we then produced an ensemble of density values, whose standard deviation is used as an estimate for the density error. Similarly, and using the functional dynamic relationships among variables, we estimated the errors associated with the dynamic height and geostrophic velocity. The standard deviations obtained with this method are less than $0.02 \mathrm{~kg} \mathrm{~m}^{-3}$ for potential density, less than $0.2 \mathrm{~m}^{2} \mathrm{~s}^{-2}$ for dynamic height, and \pm 0.2 $\mathrm{Sv}$ for geostrophic transport. These error estimates are of the same order as the differences between inferred and in situ values to be discussed next.

\section{Inferring dynamic quantities}

Different dynamic quantities may be inferred from single temperature data with the help of the above $S(T)$ analytic relations. In order to assess the goodness of this approach we compared these inferred values with those derived from the BIO Hespérides autumn 1997 cruise. The deviation between inferred and in situ calculations of dynamic height nowhere exceeds $0.2 \mathrm{~m}^{2} \mathrm{~s}^{-2}$. This value was similar to that reported by Siedler and Stramma (1983), which meets the requirements posed by Emery (1975) and Emery and Wert (1976).

Figures $7 \mathrm{a}$ and $7 \mathrm{~b}$ present the in situ geostrophic velocities and the differences between these and the inferred velocities (relative to $750 \mathrm{~m}$ ). The differences are of order $10^{-3} \mathrm{~m} \mathrm{~s}^{-1}$ and increase to about $5 \times 10^{-3} \mathrm{~m} \mathrm{~s}^{-1}$ near the surface, being typically one order of magnitude smaller than the in situ geostrophic values. The maximum velocity difference (about $10^{-2} \mathrm{~m} \mathrm{~s}^{-1}$ ) is observed in the northeastern-most station, close to the Gibraltar Strait, but again this is one order of magnitude smaller than the in situ geostrophic values. These results show the ability of the method to infer geostrophic velocities up to the sea surface despite the presence of the seasonal changing surface mixed layer.

\section{CONCLUSIONS}

We have obtained polynomial relations for salinity as a function of temperature in the surface and upper-thermocline (Eastern North Atlantic Central Water) layers of the eastern North Atlantic subtropical gyre, from $26^{\circ} \mathrm{N}$ to $38^{\circ} \mathrm{N}$ and from the African and Iberian Peninsula coast to $29^{\circ} \mathrm{W}$. The spatial resolution of the polynomials is $2^{\circ} \times 2^{\circ}$ in latitude and longitude except in some locations where, because 

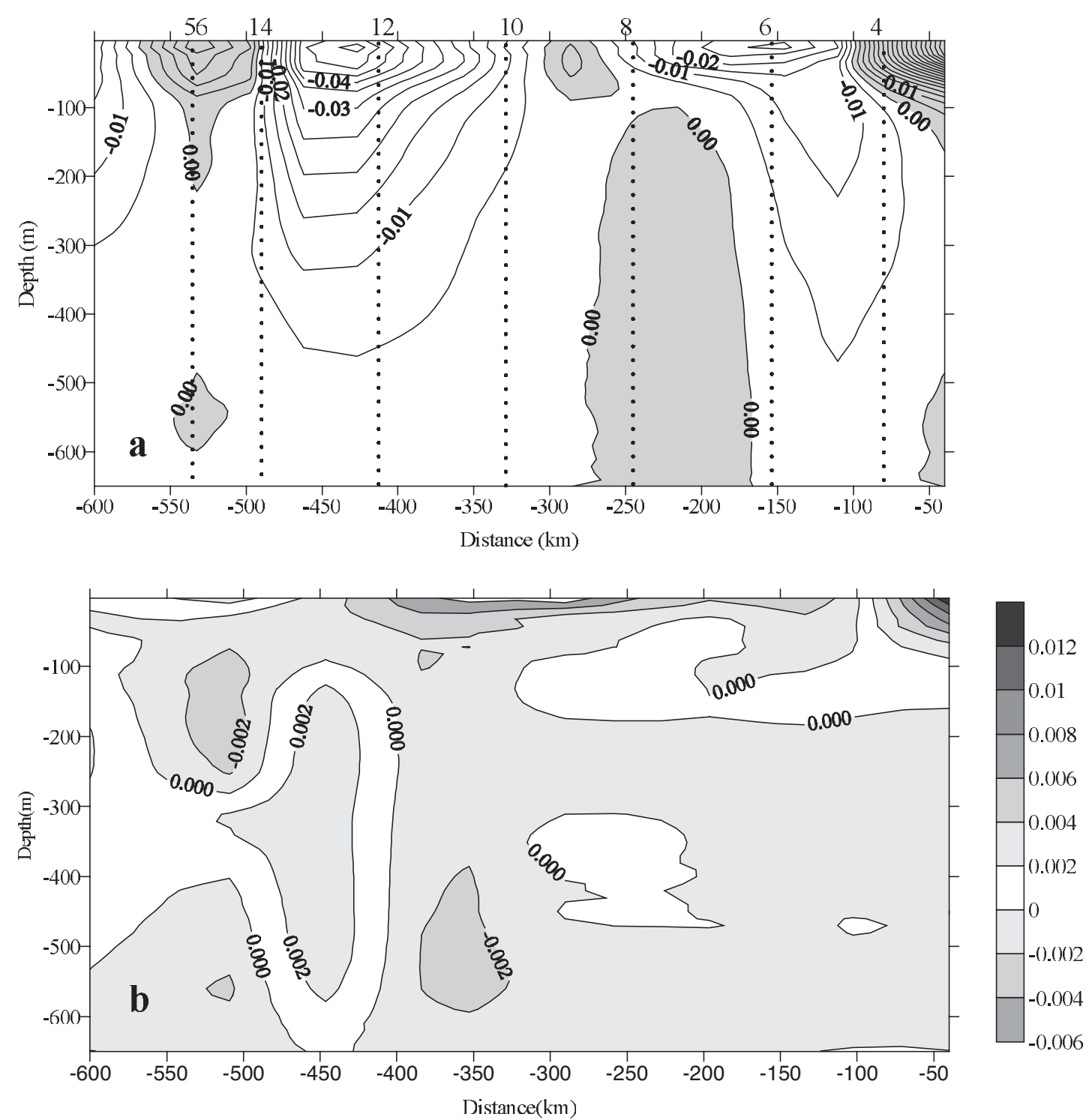

FIG. 7. - (a) Geostrophic velocities as calculated from in situ independent CTD data, the grey region corresponds to positive (offshore) values. (b) Difference between absolute geostrophic velocities as obtained from in situ CTD data and absolute geostrophic velocities estimated using temperature data and the polynomial relations. Positive values indicate that the absolute value of the in situ geostrophic velocity is greater than the absolute value of the estimated geostrophic velocity.

of the lack of sufficient data points, an alternative polynomial relation was derived for boxes of sizes up to $4^{\circ} \times 4^{\circ}$ in latitude and longitude.

The data employed for our analysis comes from historical databases as well as from recent cruises in the area by the Institut für Meereskunde and the Universidad de Las Palmas. These data have been carefully scrutinized to eliminate measurements of dubious quality, without recurring to objective methods that usually estimate the mean and deviations including data with systematic errors. This is very laborious but has the advantage that it retains a maximum number of data points. The resulting polynomials are very easy to implement and provide an improved spatial resolution as compared with previous work for the area.

We have assessed the skill of the method to estimate several dependent dynamic quantities. This was done by examining the differences between the quantities inferred solely from temperature data (both with the polynomial relations and using climatological data bases) and those obtained from independent CTD data. The polynomials reproduce the actual density values significantly better than climatology, except where intermediate waters (MW and AAIW) are present. The polynomials also do a good job at reproducing dynamic quantities such as dynamic height and geostrophic velocity. Dynamic 
height deviations are within a value $\left(0.2 \mathrm{~m}^{2} \mathrm{~s}^{-2}\right)$ considered as adequate (Emery, 1975; Emery and Wert, 1976), while errors in the geostrophic velocity are usually one order of magnitude lower than the actual values. The relatively small difference between inferred and in situ quantities is confirmed by applying the Monte Carlo approach to simulate deviations in the measured variables.

\section{ACKNOWLEDGEMENTS}

We are grateful to the Institut für Meereskunde and IFREMER for making their data sets available. The authors are very grateful to Michaella Knoll for her help with the data sets, and to our reviewers for several useful comments. The Spanish cruises that gathered some of the data analyzed here were carried out through projects from the Spanish government (program CYTMAR) and the European Union (program MAST). This work has been carried out with the support of the Spanish Government through project FRENTES (AMB95-0731) and the European Union through projects CANIGO (MAS3-CT96-0060) and OASIS (EVK3-CT-200200073). Part of this work was written while JLP was at the University of Wisconsin-Madison with funding from the Secretaría de Estado de Educación y Universidades of the Spanish government.

\section{REFERENCES}

Armi, L. and N.A. Bray. - 1982. A standard analytic curve of potential temperature versus salinity for the western North Atlantic. J. Phys. Oceanogr, 12: 384-387.

Conkright, M., R.A. Locarnini, H. Garcia, T. O’Brien, T. Boyer, C. Stephens and J. Antonov. - 2002. World Ocean Atlas 2001: Objective Analyses, Data Statistics, and Figures, CD-ROM Documentation. National Oceanographic Data Center, Silver Spring, MD, $17 \mathrm{pp}$.

Emery, W.J. - 1975. Dynamic height from temperature profiles. $J$.
Phys. Oceanogr., 5: 369-375.

Emery, W.J. and R.T. Wert. -1976. Temperature-salinity curves in the Pacific and their application to dynamic height computation. J. Phys. Oceanogr., 6: 613-617.

Emery, W.J. and A. O'Brien. - 1978. Inferring salinity from temperature or depth for dynamic height computations in the North Pacific. Atmosphere-Ocean, 16: 348-366.

Emery, W.J. and J.S. Dewar. - 1982. Mean temperature-salinity, salinity-depth and temperature-depth curves for the NorthAtlantic and the North Pacific. Prog. Ocean., 11: 219-305.

Flierl, G.R. -1978. Correcting expandable bathythermograph (XBT) data for salinity effects to compute dynamic heights in Gulf Stream rings. Deep-Sea Res., 25: 129-134.

Hammersley, H.J.M. and D.C. Handscomb. - 1983. Monte Carlo Methods. Monographs on statistics and applied probability. Chapman and Hall, New York.

Hernández-Guerra, A., F. Machín, A. Antoranz, J. CisnerosAguirre, C. Gordo, A. Marrero-Díaz, A. Martínez, A. W. Ratsimandresy, A. Rodríguez-Santana, P. Sangrá, F. LópezLaatzen, G. Parrilla and J.L. Pelegrí. - 2002. Temporal variability of mass transport in the Canary Current, Deep-Sea Res. II, 49: 3415-3426.

Levitus, S., R. Gelfeld, T. Boyer and D. Johnson. - 1994. Results of the NODC and IOC Oceanographic Data Archaeology and Rescue Projects. Key to Oceanographic Records Documentation No. 19, NODC, Washington, D.C.

Machín, F., J.L. Pelegrí, A. Marrero-Díaz, I. Laiz and A.W. Ratsimandresy. - 2006. Near-surface circulation in the southern Gulf of Cadiz. Deep-Sea Res. II, in press.

Marrero-Díaz, A., J.L. Pelegrí, A. Rodríguez-Santana and P. Sangrà. - 2001. Applicability of T-S algorithms to the Canary Islands region, Sci. Mar., 65 (Suppl. 1):195-204.

Pelegrí, J.L., A. Marrero-Díaz, A.W. Ratsimandresy, A. Antoranz, J. Cisneros-Aguirre, C. Gordo, D. Grisolía, A. HernándezGuerra, I. Laiz, A. Martínez, G. Parrilla, P. Pérez-Rodríguez, A. Rodríguez-Santana and P. Sangrà. - 2005. Hydrographic cruises off northwest Africa : the Canary Current and the Cape Ghir region, J. Mar. Syst., 54: 39-63.

Pérez, F.F., L. Mintrop, O. Llinás, M. González-Dávila, C.G. Castro, M. Alvarez, A. Körtzinger, M. Santana-Casiano, M.J. Rueda and A.F. Ríos. - 2001. Mixing analysis of nutrients, oxygen and inorganic carbon in the Canary Islands region. J. Mar. Syst., 28: 183-201.

Rodríguez-Santana, A., J.L. Pelegrí, P. Sangrà and A. MarreroDíaz. - 1999. Diapycnal mixing in Gulf Stream meanders. $J$. Geophys. Res., 104: 25981-25912.

Sánchez del Río, C. - 1989. Análisis de errores. EUDEMA Universidad- Texto de apoyo, Madrid.

Siedler, G. and L. Stramma. - 1983. The applicability of the T/S method to geopotential anomaly computations in the Northeast Atlantic. Oceanol. Acta, 6: 167-172.

Stommel, H. - 1947. Note on the use of the T-S correlation for dynamic height anomaly computations. J. Mar. Res., 2: 85-92.

Zantopp, R.J. and K. Leaman. - 1984. The feasibility of dynamic height determination from moored temperature sensor. J. Phys. Oceanogr., 14: 1399-1046.

Scient. ed.: J. Font

Received June 28, 2005. Accepted October 25, 2005. 
